\title{
Construção da identidade do mundo novo: a mestiçagem nas pinturas mexicanas do século XVIII
}

Mayara Viana Flores ${ }^{1}$

DOI 10.20396/eha.vi14.3377

\section{Introdução}

Tanto a sociedade mexicana como a sociedade brasileira como as conhecemos são construções feitas ao largo dos séculos, no qual seu principal impacto e introdutor no que se resulta atualmente, são as diferentes colonizações nestes países. A inserção dos mundos: espanhol e português, respectivamente, nas terras descobertas pelos europeus, fez com que gerassem não somente um 'novo mundo', mas também os conflitos e as batalhas para conquistar tais locais versus nativos defender a terra e suas vidas.

Tais semelhanças nos inícios das formações, como seus objetivos de estar dentro das novas terras, conquistá-las, roubar suas riquezas e provocar inúmeras batalhas entre os nativos e estes que acabara de chegar, vão se modificando ao largo do tempo, pois se encontravam diferenças em seus colonizadores, estratégias de exploração, de combate, as faunas e floras e os colonizados.

Entretanto, com o triunfo dos europeus podendo lograr seus desejos e dominarem os que habitavam as novas terras, transformá-los em escravos, uma vez que perderam o poder e o direito de serem livres, instauraram seus novos governos, criando suas leis, impondo sua fé Católica Apostólica Romana aos descrentes de um único Deus.

Desse modo, a construção de uma nova sociedade com misturas de conhecimentos e de linhagens foi surgindo fazendo com que o número da população crescesse, expandindo para as novas terras cada vez mais exploradas e assim, os dominadores espanhóis se depararam com uma nova situação: necessidade de controlar o aumento e dar continuidade com o seu poder sobre os mesmos.

Este trabalho aborda alguns aspectos sobre a sociedade vice reinal mexicana, suas seme-

\footnotetext{
1 "Esta publicação faz parte da pesquisa desenvolvida na graduação intitulada "construção da identidade do mundo novo: a mestiçagem nas pinturas mexicanas do século XVIII", orientada pelo Prof. Dr. André Luiz Tavares Pereira, desenvolvida no Departamento de História da Arte da Universidade Federal de São Paulo.
} 
Ihanças e diferenças, a convivência entre os espanhóis, índios e negros que formaram a base da miscigenação, a construção de uma cultura que nasceu pelos meios das misturas das diversas sociedades que proliferaram.

Seus cotidianos, familiares, vestimentas, ferramentas, seus ofícios, ânimos interligados de acordo com suas raças são representados em diversas pinturas criadas no século XVIII muitas com pintores identificados e outros anônimos. Também se busca analisar os motivos para o surgimento deste tipo de pintura e a sua representatividade diante da realidade mexicana do século XVIII.

\section{Sociedade da Nova-Espanha}

Desde o princípio da colonização na América, mais especificamente na região denominada de Nova Espanha, hoje o México, se constituiu de forma singular tanto por sua diversidade étnica e organização político-social. Como processo de dominação e exploração das terras e de seus nativos, também se fez presente o aumento gradativo da população ao decorrer dos anos, no qual tem suas raízes culturais e sociais essencialmente grupos indígenas e espanhóis, este com maior dominação de poder sobre o outro.

Devido a isto, no Novo Mundo Hispânico-americano começou-se a nomear aos diferentes grupos que haviam e surgiam devido as mesclas. As primeiras nomenclaturas surgiram no século XVI: gachupines (espanhóis), criollos (filhos de espanhóis que nasceram na América), mulato (filho de um espanhol com uma negra) e mestiços (filho de um espanhol com uma índia).

O primeiro caso que temos conhecimento histórico da mistura entre dois povos, se deve a relação de Hernán Cortés, um espanhol, que tinha a tarefa de conquistar e colonizar a Nova-Espanha, e Malinche, uma índia nahuatl que o ajudou na conquista sendo sua intérprete, intermediária e conselheira. Dessa junção não oficial, nasceu o fruto do breve relacionamento, o primeiro mexicano e mestiço, chamado de Martín Cortés.

A partir desse momento, uma nova sociedade que estava surgindo devido às novas mesclas, surgiram diversas nomenclaturas para designar as raças que cada vez se distanciavam da "pureza" dos três grupos principais: o espanhol, o índio e o negro. No século XVIII se intensificou não somente a quantidade de nomes para designar as misturas das novas combinações raciais, mas também a sua popularização, principalmente entre os espanhóis, os que detinham o poder na colonial. Assim, conforme em muitos documentos, obtiveram-se, como por exemplo: Zambo (Negro e mestiço), Mourisco (mulato de pele escura), castizo (mulato de pele clara). 
Existiram também classificações que englobam nomes relacionados a animais, como lobo e coyote e alguns que fazem alusão a indeterminação racial devido a uma mistura de raças que foram compostas por muitas gerações de diversas mesclas até chegar numa determinada que consideravam impossível nomina-la, e as consideravam como "tente en el aire" e "no te entiendo".

Esse sistema classificatório racial se deve a criação ideológica que propõe subestimar como superior os de "raça pura", ou seja, os invasores e colonizadores, os espanhóis, e inferiorizar os nativos da terra da Nova Espanha e os negros trazidos do continente africano. O primeiro grupo desde sua chegada buscou analisar, fazer aliados e por fim "conquistar", não somente as terras, mas suas riquezas e o povo que a habitavam. Governavam conforme lhes convinha para a manutenção de seus privilégios e do rei da Espanha. Uma relação criada entre o conquistador e o conquistado.

O século XVIII no México, carregou o resultado desse sistema até então, que imperou na sociedade em seus aspectos sociológico, econômico e cultural. Nessa dita época, a Nova Espanha se encontrava num "boom" populacional, no qual era composto por sua maioria das inevitáveis mestiçagens, o que ocasionou delimitações do crescimento social e econômico, como também na distribuição de riquezas e de posição laboral.

A mestiçagem foi um fenômeno do resultado do contato sexual entre os três principais grupos étnicos: espanhóis, índios e negros. Ao passar por gerações e gerações misturas de raças, houve o crescimento de tais castas que não obtemos informações concretas de quantas pessoas estavam englobadas em cada grupo. De acordo com Alexander Von Humboldt, conhecido por suas expedições em muitos países, podendo contribuir na ciência e outras áreas do conhecimento por suas viagens pelo mundo, inclusive no México.

As possessões do rei da Espanha em América superam por sua extensão as vastas regiões que abarcam na Ásia, tanto o império russo como da Grã-Bretanha. [...] Espanha por sua superfície é equivalente a quinta parte do México [...] em menos de meio século a população deste último reino será igual à da metrópole. ${ }^{2}$

Com o avanço da mestiçagem, no século XVIII o número de mestiços era maior que os espanhóis e os ameríndios, devido a isto, Ihes propagaram uma imagem degradante, subestimando-os e os julgando a desordeiros. Pois conforme seu crescimento, o grupo dominante se sentiu ameaçado de uma possível revolta e conquista do poder. Assim a desqualificação ao outro era cada vez mais usada, tal como reforçado o uso das castas no intuito de diminuir a sua confiança em busca de

\footnotetext{
2 HUMBULDT, 2011, p. 73
} 
melhorias em sua posição na sociedade e evitar uma usurpação pelos mestiços.

Após a chegada dos colonizadores o declínio demográfico teve seu aumento gradativo ao passar dos séculos, no qual as doenças da época tais como: sarampo, varíola, febre amarela, peste bubônica entre outros, foram os agentes para tal acontecimento catastrófico, afetando principalmente os nativos que não eram imunes, não tinham imunidade para tais enfermidades, uma vez que os espanhóis conviviam há séculos com essas doenças.

Para Alejandro Humboldt, durante sua passagem pela Nova Espanha ao princípio do século XIX, de acordo com seus cálculos, a população era em torno de cinco milhões de habitantes, metade era composto de índio e a outra parte era entre os diversos mestiços, os brancos (tanto espanhóis como os criollos) e os negros africanos. Devido a isto, podemos levar em conta que após três séculos depois da colonização a sociedade já composta no século XVIII era a criação do povo mexicano, uma vez que o número de estrangeiros, os espanhóis nascidos na Espanha eram em setenta mil e os negros africanos trazidos como escravos eram seis mil e cem pessoas.

Na época citada devido à grande miscigenação entre as raças, eclodiu diversas questões nos âmbitos raciais, sociais e na política. O papel tanto dos mestiços como dos criollos causaram instabilidades que se intensificaram ao decorrer dos séculos e causaram preocupação no poder político. Este primeiro filho de espanhol e mãe índia, uma das primeiras e de maior número do fruto desse tipo de relação, se encontravam numa situação no qual não se identificavam em nem grupo social-racial e tão pouco eram aceitos. Uma vez que os criollos, filhos de espanhóis e que nasceram na américa hispânica, se sentiam por direito e buscavam estar inseridos na condição social, econômica e política dos ditos "puros" espanhóis, porém eram ignorados e menosprezados por este último.

O conflito social emergiu sob as influências da criação das castas pelos espanhóis, no qual se determinavam com o "sangue puro" e devido a isto, eram os detentores de altos poderes sobre a Nova Espanha, detinham os maiores cargos políticos, econômicos e alta posição na sociedade. Tanto os mestiços com os índios e os negros como os criollos tinham esse sentimento, que causava oposição entre eles, o que resultou a origem da violência que perpetua até os dias atuais no México.

Com o decorrer houve um relativo desequilíbrio social, que tomou com o tempo uma importância crescente e se criou uma fronteira social. Tais grupos raciais eram considerados uma ameaça ao poder espanhol, de modo que cada vez mais aumentavam as relações e se tornavam mais de "sangue impuro", o número dos que detinham o poder, um grupo heterogêneo, diminuía cada vez mais, a insegurança tomava conta deste último, a necessidade de deter qualquer possível revolta ou a possibilidade de tomarem o poder emergiu, principalmente por aqueles que se acreditavam mais 
injustiçados e merecedores de sua herança de privilégios por serem filhos direto de espanhóis, os criollos.

A formação do sistema de castas foi criada pelo pensamento que teve em base, ao chamado, atualmente, de "biopoder"3 pelo filósofo francês Foucault, no qual o papel da medicina foi fundamental para a construção social-racial institucionalizada na Nova Espanha e para o funcionamento de um sistema opressivo. A manifestação das pinturas foram o resultado da construção do pensamento hispânico concretizada, uma vez que o grupo homogêneo necessitava para poder controlar a sociedade, diminuindo a possibilidade de uma revolta.

O uso da imagem como forma de persuasão se perpetua desde o início da colonização espanhola até os dias atuais que se encontra intrínseca no México. De acordo com Gruzinski, em seu livro "A guerra das imagens", no início da colonização, com os primeiros contatos com os nativos houve um estranhamento, de modo que tinham que lidar com o convívio de uma cultura divergente, surgiu então a necessidade de se adaptar à realidade presente no local, agir distinto do que estavam familiarizados, à educação que aprenderam no Velho Mundo.

Com isso tinham por objetivo na aproximação com os povos, adquirir conhecimentos de seus costumes e crenças para que pudessem utilizar a seu favor na busca pela conquista de terras e das riquezas que haviam como os metais preciosos. Uma de suas grandes estratégias mais irrefutável seria sua relação com os povos nativos, como por exemplo, a união entre o espanhol e uma índia, o que facilitou a parte de comunicação. Um dos aspectos para se levar em consideração nestes primeiros momentos, o sentimento de estranhamento era recíproco, no qual os nativos não tinham tido contato com "seres estranhos" e menos com os objetos que estes trouxeram.

Assim com as relações entrelaçadas criou uma população de mestiços que tiveram um aumento significativo, no qual foi de grande utilidade aos espanhóis em suas conquistas no primeiro momento. Devido a isto, este como consequência o número elevado de mestiços, no qual gerou preocupação na coroa Espanhola que estava perdendo o controle da natalidade e que por sua vez, uma quantidade cada vez menor de espanhóis.

Com o surgimento dos novos grupos, foram subjugados como inferiores por sua falta de "pureza" no sangue, interligados a imagem de causadores de desordem, delinquência, uma ameaça aos possuidores de privilégios e poderes na Nova Espanha.

3 Termo criado pelo filósofo francês Michel Foucault entre 1974-1979 que se refere a prática do estado moderno que utilizam de técnicas para poder praticar a subjugação dos corpos e o controle da população. 


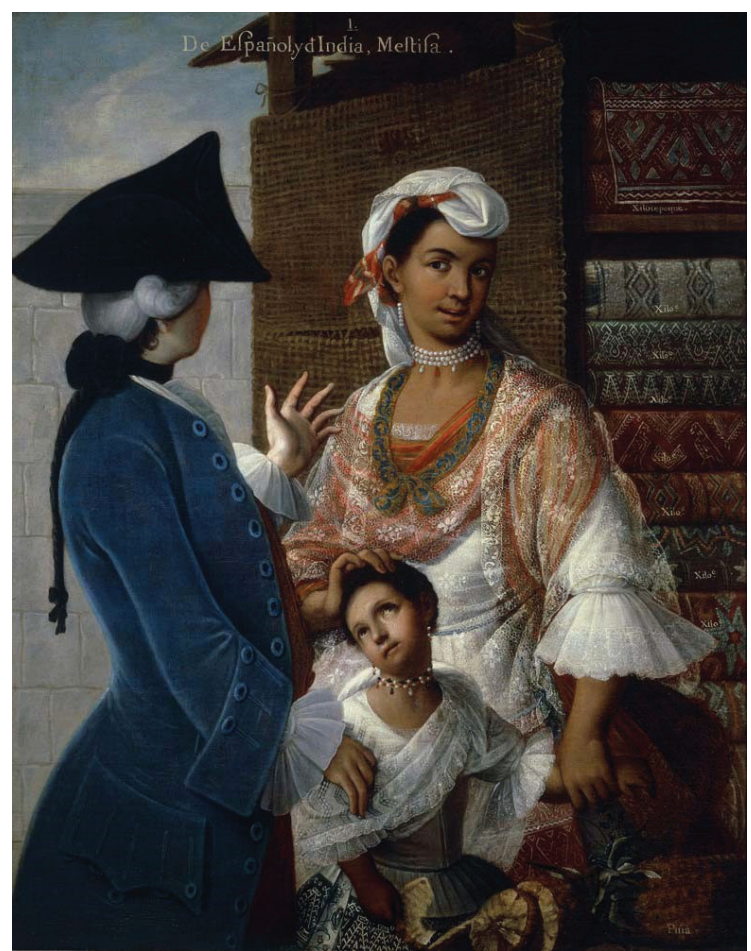

[Figura 01] Miguel Cabrera. De Español e india, mestiza, siglo XVIII.

Óleo sobre tela. 147 x $117 \mathrm{~cm}$. Coleção particular. Galeria de castas mexicanas, Museo de Historia mexicana. México.

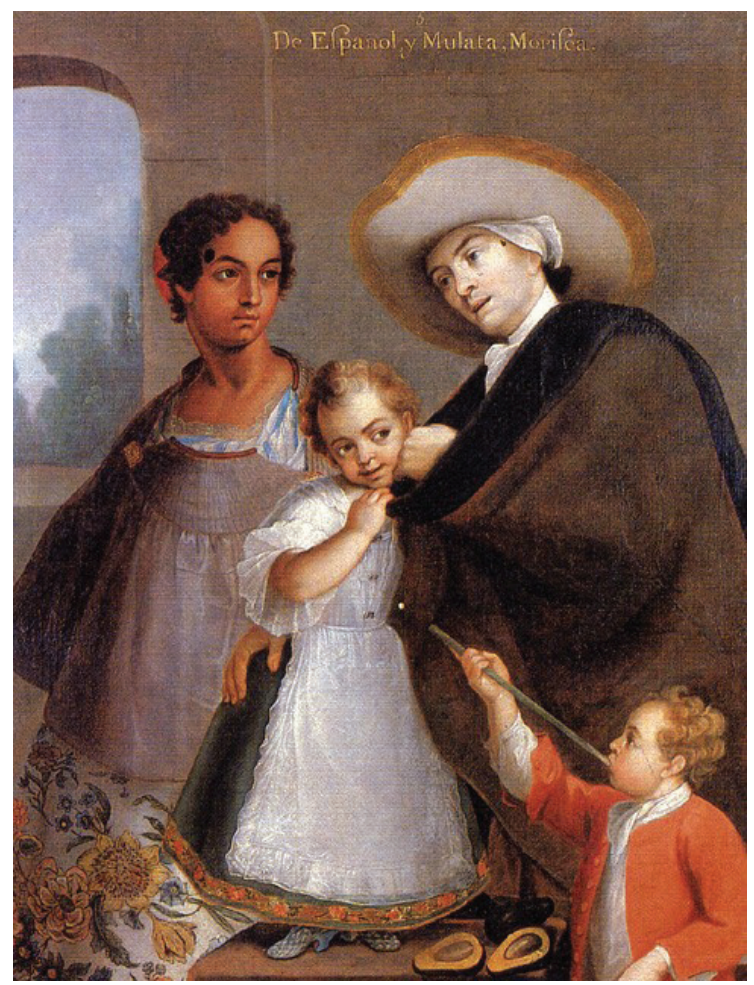

[Figura 03] Miguel Cabrera. De Español y mulata, morisca, 1763.

Óleo sobre tela. 136 × 105 cm. Coleção privada.

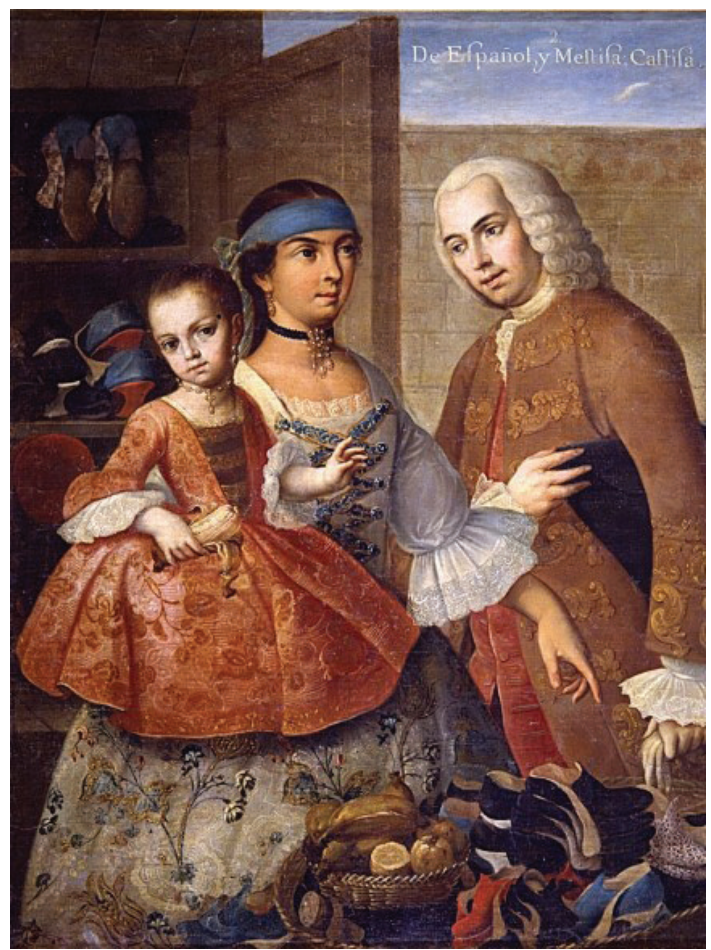

[Figura 02] Miguel Cabrera. De Español y mesti$z a$, castiza, 1763.

Óleo sobre tela. $132 \times 101 \mathrm{~cm}$. Museu de América. Espanha.

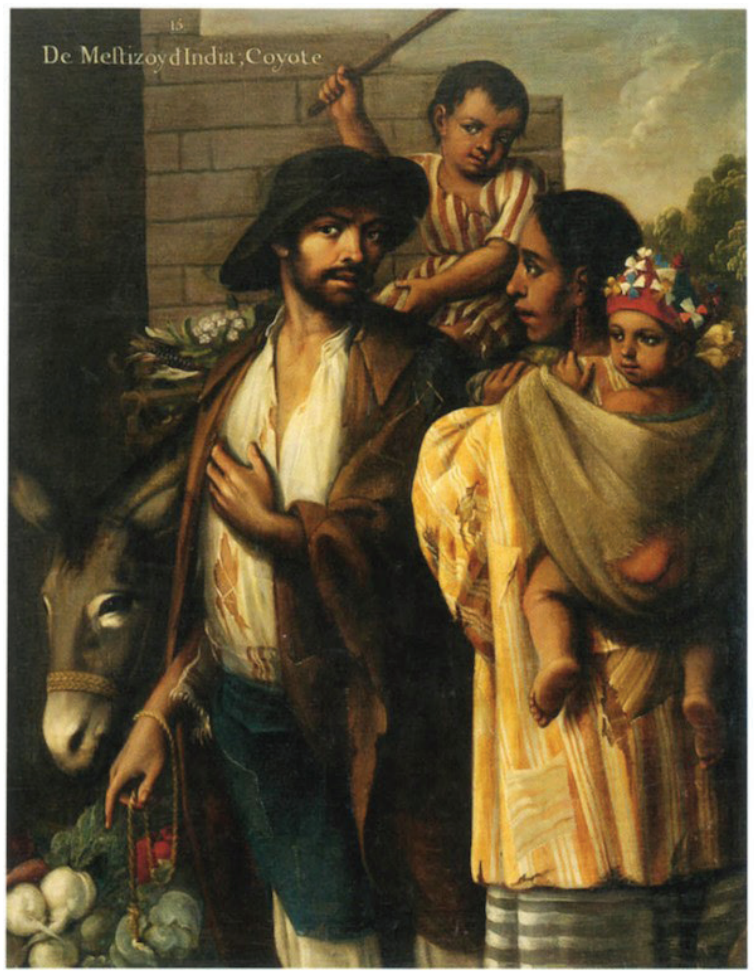

[Figura 04] Miguel Cabrera. De Mestizo e India, Coyote, 1763.

Óleo sobre tela. 


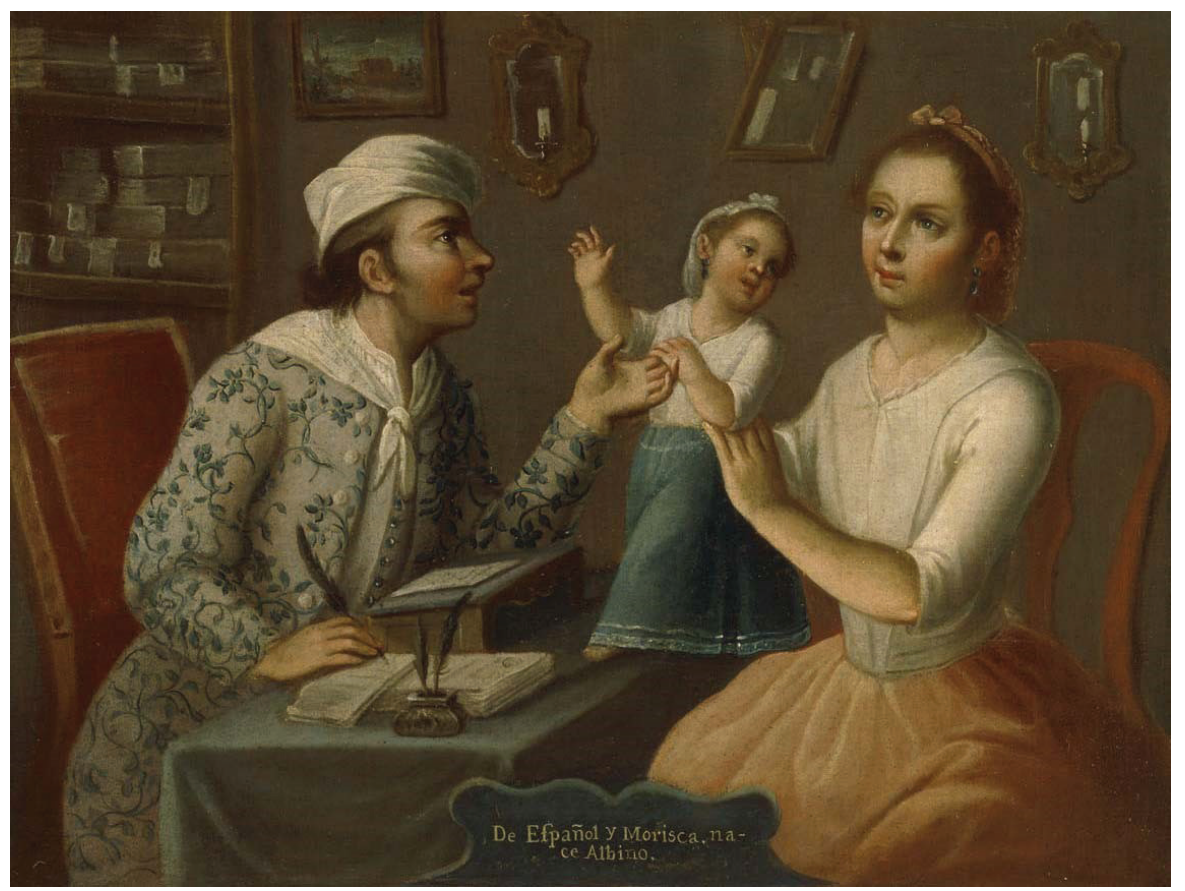

[Figura 05] Miguel Cabrera. De Español y Morisca, nace Albino. Século XVIII. 49,5 × 62,3 cm. Museu de história mexicana, México.

II. A sociedade de castas na pintura: representação de um olhar

A ideologia do sistema de castas foi tema representado na pintura oitocentista, se tem documentado que a primeira encomenda foi em 1710 feita pelo vice-rei Fernando de Alencastre Noronha e Silva ao pintor Juan Rodriguez Juárez, com o intuito, primeiramente, de mostrar ao rei Felipe $V$, a sua corte e as pessoas que faziam parte da elite espanhola, as mesclas das raças da colônia. Segundo Ilona Katzew (2004, p. 69), "Referências documentais indicam que uma série de pinturas de castas iniciais foram encomendadas por vice-reis e funcionários eclesiásticos".

Esse gênero artístico representa pictoricamente a linha de pensamento no qual seguiam os colonizadores, de modo que, controlavam tudo o que era produzido no mundo artístico, literário e histórico. A mentalidade de uma cultura europeia, que se colocavam na posição de vencedores sobre o outro após o processo de colonização, dos civilizados e religiosos contra os bárbaros, estes eram os povos que não estavam inseridos no mundo europeu, o centro do mundo.

As pinturas de castas carregam um lado da história, uma construção de pensamentos e ações, tal como a reforma Bourbônica, o olhar de superioridade ao outro, dos que precisam da civilidade do colonizador para melhorar a sua condição social e econômica, e de seu descendente, porém não havendo a possibilidade de se ascender tal como o espanhol, visto o único que carrega sangue puro. 
Após a mistura entre o espanhol e a índia, os maiores componentes dos dois grupos, e ressaltando que, neste período colonial houve grande número de casos de um espanhol com mais de uma índia, estas que foram muitas vezes violentadas sexualmente, geraram o que se chama de "mestiço".

Uma das características que chama atenção neste tipo de pintura são suas nomenclaturas, os nomes designados para as raças: "De Español y d'India, Mestiza”; "De Español y Mestiza, Castiza”; “De Español y Negra, Mulata”; "Español y Mulata, Morisca”; “De Español y Morisca, Albina”; "De Español y Albina, Torna Atrás"; "De Negro y d'India, Lobo"; "De Indio y Mestiza, Coyote” ; "De Negro y d'India, Chino Cambujo", entre outros.

Percebe-se que em alguns casos são representadas as mesmas misturas de castas, porém o resultado destas recebem nomes de diferentes castas. As criações desses nomes são originadas de um conjunto de fatores que se perpetuaram e foram sendo expandidos pelas terras da Nova Espanha.

Algunos historiadores argumentan que la mayoría de estos nombres no se utilizaban en la vida cotidiana de la población y que fueron inventados por miembros de la élite o por los mismos pintores de serie de castas, mientras otros defienden la posibilidad de que hayan nacido justamente del lenguaje informal de la calle ${ }^{4}$

Esses nomes têm suas diversas origens e significados, como foram influenciadas pela linguagem indígena, entre suas diversas tribos, árabe, espanhola e até mesmo do português utilizado no Brasil, como a palavra "Criollo" que se deriva da palavra "Crioulo", que eram filhos dos africanos escravizados.

Dentre esses nomes existem os que são relacionados ao reino animal, ou seja, a pessoa integrada a esta casta pode ser comparada e igualada a um animal, irracional, feroz, violento, será uma pessoa agressiva e sem educação, um ser bárbaro, estas castas são: coyote, lobo, mulata que vem da palavra mula e cambujo.

Desde na nomenclatura das palavras, na representação feita nas pinturas e até mesmo em muitas delas, se encontram um tipo de legenda no qual além de informar as castas presentes, há o julgamento das características emocionais, psicológicas e comportamentais da criança, que muitas vezes se encontra ainda na fase de um bebê, de modo que não foi desenvolvido ainda sua personalidade, como podemos ver em muitas pinturas de José Joaquín Magón. Desse modo definem em suas concepções como eles serão, se embasando nas castas de seus pais, logo sua origem, na cor de

4 HERNANDEZ, 2017, p.46 
sua pele e conforme são as pessoas classificadas nas mesmas castas que as suas.

Assim é feita e perpetuada uma hierarquização de raças, tanto entre as próprias pinturas, como também a posição do autor, quem encomenda, o artista que reproduz ou de quem concebe estas ideias, sobre o objeto retratado. Uma mentalidade que existia verbalmente, no plano das ideias e se concretizou na pintura, o que acarretou numa expansão potente da racialização e préconceito sobre o outro, crescendo tanto esse tipo de olhar na Nova Espanha como também na Espanha e outro países por onde percorreram as obras naquela época.

\section{Referência Bibliográfica}

SÁNCHEZ, Alberto Ruy et al. ARTES DE MÉXICO. La pintura de castas. Revista libro número 8. 2. ed. México D.F., 1998 KRAUZE, Enrique et al. ESPEJOS DISTANTES. Los rostros mexicanos del siglo XVIII. Primera edición. México, 2001. HERNÁNDEZ, Sofía. El artificio de las castas y la verdad de la pintura: la serie de Miguel Cabrera. 2017. 99f. Ensayo académico (Maestra en Historia del arte) - Faculdad de Filosofía y Letras, Instituto de investigaciones y estéticas, Universidad Nacional Autónoma de México, D.F.

HUMBOLDT, Alejandro. Ensayo político sobre el reino de la Nueva España. Editoral Porrúa México, séptima edición, 2011, México.

CÁZARES, Maria del Carmen León et al. HISTORIA DE LA VIDA COTIDIANA EM MÉXICO. La sexualidad y las normas de la moral sexual. El colegio de México y fondo de cultura económica, 2005, México D.F.

KATZEW, Ilona. Casta Painting: Images of Race in Eighteenth-Century Mexico. New Haven: Yale UP, 2004.

MELÉNDEZ, Fernando. Castas Novohispanas.2001.50f. Tesina (para obter el título de licenciado em Historia) - Facultad de Filosofía y Letras, Universidad Nacional Autónoma de México, D.F. 